Scandinavian family in which it was identified - that is believed to contribute to Alzheimer's disease by producing a build-up of amyloid plaque in the brain.

Researchers say that Elan transgenic mice are closely held by the firm for its drug development efforts. One researcher alleges that when Elan mice are provided to academic scientists, they are usually neutered females.

Mayo's transgenic mice, provided to more than 50 academic research groups and a dozen pharmaceutical firms, are based on work by a group headed by Karen Hsiao at the University of Minnesota.

Hsiao's group created a mouse that would express amyloid in the brain (see Science 274, 99-103; 1996). After publication, Mayo licensed the discovery from the University of Minnesota, arranged for contract breeding of the mice and began distributing them. Mayo also licensed the sequence of the Swedish mutation from a Kansas firm.

Mayo's mice are considered so valuable that there are reports of breeding trios of males being sold to companies for $\$ 850,000$. Mayo officials decline to discuss this.

When providing its mice to academic institutions, Mayo requires the signing of a material transfer agreement that gives the non-profit organization an option to buy the rights to any commercial discovery that may come from research with the mice.

This agreement - like those used by biotech firms - is considered by some to be an unusually bold move for a non-profit organization. Even some of Mayo's own

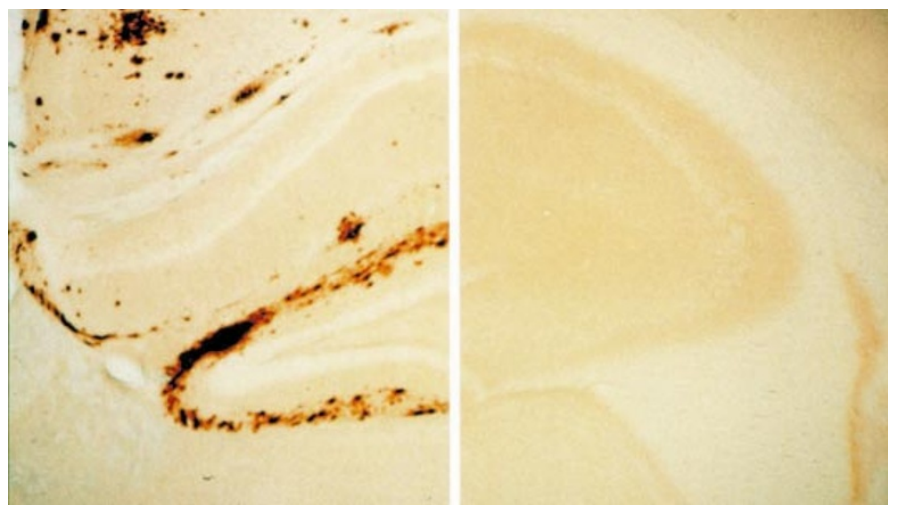

Mice work: the brain of Elan's one-year-old mouse (far left) shows characteristic plaques of Alzheimer's disease, absent from that of the similar animal (left), which was dosed with Elan's experimental Alzheimer's vaccine.

researchers have difficulty with this practice.

"My view is there should be no reachthrough agreements between non-profit institutes," says pharmacology professor John Hardy at Mayo's Jacksonville facility, whose laboratories at Imperial College London, South Florida and Mayo have produced leading discoveries and researchers.

But Steven Younkin, a physician neuroscientist and former director of research at Mayo's Jacksonville facility, defends the agreements as being necessary to cover the organization's enormous cost for the longterm, mouse-producing project. "With a non-profit institution such as Mayo, any money realized from licensing agreements goes back into research," says Younkin.

If Mayo was primarily interested in making money, he adds, it would have entered an exclusive licensing agreement for the transgenic mice with a single pharmaceutical firm. It deliberately decided not to do this, in order to make the mice available for academic research.

As neuroscientists debate these issues, subpoenas have been spreading through the neuroscience community. Earlier this month, Elan failed in a bid to require Hsiao to produce her laboratory notebooks for a deposition this week.

A number of researchers, including microbiologist David Borchelt, an associate professor of pathology at Johns Hopkins University in Maryland, are debating their options as they face subpoenas. Unable to secure the desired transgenic mice, Borchelt made his own mice.

Elan has now subpoenaed him and his lab notebooks, which he fears may be studied closely by the firm's scientists. Borchelt says he would "go to jail" rather than provide his notebooks. Rex Dalton

\title{
Computer glitch unleashes prize nomination debate
}

Boston

The normally tranquil world of statistical physics and mechanics was rocked last week by a computer glitch that led to a flurry of exchanges over nominations for the field's most prestigious prize, the Boltzmann Medal. The prize is awarded by the International Union of Pure and Applied Physics (IUPAP) once every three years.

The glitch triggered a debate between those who regarded the proliferating e-mail messages as a nuisance that threatened to overwhelm computer networks, and others who welcomed an unaccustomed openness.

The source of the problem was the 3,500strong mailing list kept by the Center for Mathematical Sciences Research at Rutgers University, which hosts two conferences on statistical mechanics each year.

Kurt Binder of the University of Mainz in Germany, who chairs the IUPAP committee that issues the Boltzmann Medal, asked Joel Lebowitz - a member of the nominating committee - to send an announcement soliciting nominations. (The next prize will be awarded in Mexico, in summer 2001.) Recipients were meant to reply to him alone, not sending their comments to each other.

Juerg Froehlich of Eidgenössische Technische Hochschule Zurich nominated John Cardy of Oxford University, also citing the work of Sasha Zamolodchikov of Rutgers. "But something went wrong," says Lebowitz. "The computer went haywire" when Froehlich hit the 'reply' button, and his suggestions went to all 3,500 on the list. Others soon joined in the nomination frenzy. Roger Bidaux of the Centre d'Etudes de Saclay in France advanced the name of Lawrence Schulman, a physicist at Clarkson University in Potsdam, New York. "I believe that our community can afford a little bit of tolerance and democracy, and allow me to express my opinion," wrote Bidaux.

University of Rochester physicist Yonathan Shapir shared this sentiment, saying he'd like to see the process conducted in a more open, democratic fashion.

"There is a lot of secrecy in academia," says Shapir. "I don't like the way this business is handled, with just a few people making decisions for the rest of us." The Internet, he adds, "could allow us to hold large 'town meetings,' where many people voice their opinions and, in the end, a vote is taken".

Several respondents, though, argued that nominations should not be aired in public.

Meanwhile, Haym Benaroya of Rutgers was anxious to avert an e-mail meltdown, and urged people to stop sending messages to the Rutgers list. "At one point, I was getting 10 to 15 e-mails every 10 minutes," he says. "With everybody talking to everybody else, things were snowballing. The whole system could have been shut down."

The snafu was corrected within a day, and an apology issued. Future nominations were requested by post, rather than e-mail.

The apology put an official end to the episode. But Shapir hopes that an important lesson might still be learned. As a result of the computer glitch, he says, "for a brief period of time, we got a glimpse of how things could be done. We don't have to cling to the secretive ways of the past." Steve Nadis 